\title{
Use of Crown Areas in Odontometric Analyses
}

\author{
S. M. Garn, C. L. Brace, and P. E. Cole \\ Center for Human Growth and Development and Department of Anthropology, University \\ of Michigan, Ann Arbor, Michigan, 48109, USA
}

Although the simple mesiodistal and buccolingual crown dimensions have long been used in population comparisons and in the analysis of congenital malformation syndromes, there are also good reasons to employ the crown areas as an approximation of the chewing surface (Brace, f Dent Res, 46:809, 1967; Brace and MaHler, Am J Phys Anthrop, 34:191, 1971). Unfortunately normative values for crown areas of individual teeth or for the permanent dentition are not available, and there is no information on the extent to which sex discrimination can be improved by use of areas.

To resolve the problem we have made both individual and group determinations of crown areas (mesiodistal times buccolingual), computer-calculated, using pooled left and right sides from optical-measuring readouts as previously described (VAN DER LINDEN et al, $J$ Dent Res, 51:1100, 1972; Moyers et al, Standards of Human Occlusal Development, 1976, pp 7-10). We have not only listed these, tooth-bytooth and for each sex separately, as in the table, but we have also estimated the amount of sexual dimorphism calculated as $100\left(\frac{M}{F}-1.0\right)$ for each tooth, and the extent of discriminatory effectiveness both tooth by tooth and for 14 permanent teeth, as also given in the table.

Received for publication January 7, 1977. Accepted for publication February 1, 1977.
As shown, the largest calculated tooth areas are those for $\mathrm{MI}_{1}$ and $\mathbf{M}^{\mathrm{x}}$ (respectively) and the smallest for $I^{2}, I_{2}$ and $I_{1}$. When the crown dimensions are expressed as areas, percent sexual dimorphism is systematically larger than when the mesiodistal measurement is used, but smaller than when buccolingual measures are employed. Tooth by tooth, the pattern of sexual dimorphism exhibited by the areas reflects canine dimorphism and the relative sex difference in crown areas reasonably resembles that obtained by squaring length or breadth measurements ( $\mathrm{r} \simeq 0.77$ ). Using discriminant analysis for up to 14 pairs of permanent teeth, crown areas provide less discriminatory effectiveness than do the mesiodistal dimensions (i.e., $77 \%$ as compared with $81 \%$ for all 14 teeth), but slightly greater discriminatory effectiveness than do the buccolingual dimensions (77\% vs. $76 \%$ ). The latter figures are taken from GARN et al, $J$ Dent Res in press, 1977.

Thus, crown areas of the permanent teeth, while useful in evolutionary comparisons and in the comparison of chromosomal and genetic abnormalities, may not afford greater sex discrimination of archaeological remains or massdisaster victims than conventional length or breadth measurements, nor add appreciably to the morphometric analysis of X-chromosome or $\mathrm{Y}$-chromosome abnormalities including the XO, XXY, XYY or XXX.

This study was supported in part by Grant DE 03610 from the National Institutes of Health.

TABLE

Means, Variabilities and Sex Discriminatory Effectiveness of Crown areas

\begin{tabular}{|c|c|c|c|c|c|c|c|c|}
\hline \multirow[b]{2}{*}{ Tooth } & \multicolumn{3}{|c|}{ Males $\left(\mathrm{mm}^{2}\right)$} & \multicolumn{3}{|c|}{ Females $\left(\mathrm{mm}^{2}\right)$} & \multirow{2}{*}{$\begin{array}{c}\text { Percent } \\
\text { Sexual } \\
\text { Dimor- } \\
\text { phism }\end{array}$} & \multirow{2}{*}{$\begin{array}{l}\text { Percent Sex } \\
\text { Discrim- } \\
\text { ination }\end{array}$} \\
\hline & $\mathbf{N}$ & Mean & $\mathrm{SD}$ & $\mathbf{N}$ & Mean & SD & & \\
\hline \multicolumn{9}{|c|}{ Maxilla } \\
\hline $\mathbf{I}^{1}$ & 105 & 67.6 & 10.7 & 95 & 60.2 & 8.3 & 12 & 63 \\
\hline $\mathrm{I}^{2}$ & 102 & 44.9 & 8.0 & 89 & 41.2 & 8.2 & 9 & 58 \\
\hline C & 79 & 61.2 & 8.7 & 65 & 52.2 & 8.5 & 17 & 72 \\
\hline $\mathbf{P}^{1}$ & 80 & 63.5 & 7.7 & 63 & 60.3 & 6.8 & 5 & 60 \\
\hline p2 & 69 & 64.0 & 6.1 & 53 & 60.0 & 7.9 & 7 & 64 \\
\hline$M^{1}$ & 109 & 115.3 & 12.1 & 97 & 106.4 & 10.3 & 8 & 67 \\
\hline $\mathrm{M}^{2}$ & 61 & 97.0 & 13.7 & 40 & 84.7 & 12.8 & 15 & 66 \\
\hline \multicolumn{9}{|c|}{ Mandible } \\
\hline$I_{1}$ & 107 & 32.4 & 3.9 & 97 & 29.7 & 3.9 & 9 & 60 \\
\hline $\mathrm{I}_{2}$ & 104 & 36.2 & 4.8 & 96 & 33.8 & 4.6 & 7 & 61 \\
\hline $\mathrm{C}$ & 87 & 48.0 & 6.7 & 74 & 42.8 & 5.2 & 12 & 66 \\
\hline$P_{1}$ & 82 & 54.6 & 6.7 & 68 & 52.1 & 7.3 & 5 & 58 \\
\hline $\mathrm{P}_{2}$ & 67 & 62.2 & 6.1 & 55 & 59.2 & 6.2 & 5 & 57 \\
\hline $\mathrm{M}_{1}$ & 108 & 112.2 & 10.1 & 97 & 103.6 & 12.0 & 8 & 66 \\
\hline $\mathbf{M}_{2}^{1}$ & 61 & 99.7 & 11.9 & 47 & 89.7 & 11.8 & 11 & 64 \\
\hline Summed & 52 & 964.8 & 85.6 & 34 & 879.3 & 75.4 & 10 & $77^{*}$ \\
\hline
\end{tabular}

* Discriminatory effectiveness for 14 tooth pairs. 